\title{
Perceived oral health and its association with symptoms of psychological distress, oral status and socio-demographic characteristics among elderly in Norway
}

Kari Elisabeth Dahl ${ }^{1 *}$ (D) Giovanna Calogiuri ${ }^{1}$ and Birgitta Jönsson ${ }^{2,3}$

\begin{abstract}
Background: There is poor knowledge about the extent to which psychological distress influences oral health in older people in Norway. The aim of this study was two-fold: i) to describe the oral health of Norwegian elderly and their levels of psychological distress; and ii) to examine the relationship of psychological distress with self-rated oral health, while controlling for oral status and socio-demographic characteristics, in Norwegian elderly.

Methods: Data were retrieved from a national cross-sectional survey conducted by Statistics Norway in 2012 and included information about self-rated oral health, psychological distress (measured using the Hopkins Symptom Checklist 25; HSCL-25), gender, age, civil status, smoking, self-reported number of teeth present and dental attendance for 949 non-institutionalised adults aged 65 years or older. Logistic regression was used to establish whether psychological distress predicts self-rated oral health, controlling for socio-demographic characteristics and oral status.

Results: Around 27\% of the elderly reported having poor oral health, and $8 \%$ had a HSCL-25 mean score $\geq 1.75$, which indicates higher levels of psychological distress. Among the symptoms listed in the HSCL-25, the most frequently reported problems were lack of energy $(1.7 \pm 0.8)$ and difficulties falling and staying asleep (1.6 \pm 0.7$)$. The likelihood of reporting poor oral health was independently associated with having a mean HSCL-25 score $\geq 1.75$ $(\mathrm{OR}=1.89 ; 95 \% \mathrm{Cl}=1.14-3.15)$, even when smoking $(\mathrm{OR}=1.83 ; 95 \% \mathrm{Cl}=1.17,2.87)$ and having fewer than 20 teeth $(\mathrm{OR}=3.49 ; 95 \% \mathrm{Cl}=2.56,4.76)$ were taken into account.

Conclusion: Most of the Norwegian elderly in our sample perceived themselves to have good oral health and reported relatively low levels of psychological distress. Higher levels of psychological distress can influence the oral health of the elderly independently of other factors such as smoking and having reduced number of teeth. Dental care professionals should consider screening their elderly patients for psychological distress and individualise the information about dental care for this specific population.
\end{abstract}

Keywords: Ageing, Mental health, Depression, Older adults, Epidemiology

\footnotetext{
* Correspondence: kari.dahl@inn.no

${ }^{1}$ Department of Public Health, Faculty of Social and Health Sciences, Inland

Norway University of Applied Sciences, Hamarveien 112, 2418 Elverum,

Norway

Full list of author information is available at the end of the article
}

(c) The Author(s). 2018 Open Access This article is distributed under the terms of the Creative Commons Attribution 4.0 International License (http://creativecommons.org/licenses/by/4.0/), which permits unrestricted use, distribution, and reproduction in any medium, provided you give appropriate credit to the original author(s) and the source, provide a link to the Creative Commons license, and indicate if changes were made. The Creative Commons Public Domain Dedication waiver (http://creativecommons.org/publicdomain/zero/1.0/) applies to the data made available in this article, unless otherwise stated. 


\section{Background}

As in other European countries, in Norway an increasing decline in fertility rates and increased life expectancy are resulting in an increase of the proportion of older people which represent a potential burden to society and a challenge to public health institutions [1](WHO). Compared with other European countries, only Poland, Iceland and Ireland have fewer elderly people than Norway [2]. However the population age is increasing at varying rates. For example, the proportion of the Norwegian population aged 65 years and older in 2015 was 16.3\%, an increase from $8.4 \%$ in 2006. In order to ensure people's quality of life and to minimise increased public costs, it is important to understand how to promote good health among the increasing number of older citizens.

One challenge in becoming elderly is maintaining good oral health, especially for fragile or cognitively impaired older persons, which is one of the reasons why elderly people have received increasing attention from researchers and health policy makers [3]. To maintain good oral health is, an important component of a healthy ageing [4]. A number of dental conditions are associated with older age, such as dry mouth (xerostomia), root caries, and periodontal disease [5-7]. Periodontitis, which may result in tooth loss, is still a common disease and its prevalence is reported by European and US studies to range from $31 \%$ to $76 \%$ [8-10]. Furthermore, its prevalence and severity increase with age $[6,7]$. During recent decades, a reduction in the prevalence of edentulousness and the prevalence and incidence of tooth loss has occurred in many countries $[11,12]$. Despite these observed declining trends in edentulousness, the mean number of lost teeth increases with increasing age and a substantial proportion of the current older generations experience tooth loss [11, 13]. Furthermore, studies have confirmed the expected positive associations between tooth loss and reduced perceived oral health $[13,14]$.

While most of the elderly have good mental health and psychological well-being, many are at increased risk of developing mental disorders [15]. Symptoms of psychological distress are common and serious, causing significant disruption in daily living. Mental disorders account for circa $7.4 \%$ of the global burden of disease and will probably steadily increase in the future [16]. Psychological distress is often under-recognised and under-treated in primary care [17]. Psychological distress is so widespread that it can be considered one of the most common health problems in Norway [18]. It is estimated that about $30 \%$ of the Norwegian population experience high levels of psychological distress at some time during their lifetime [18]. Psychological distress is highly prevalent in the elderly and often has negative consequences on their everyday life, such as leading to a reduced quality of life [19]. Increased psychological distress might also have a negative impact on the elderly's health-related behaviours, including their dietary patterns as well as their dental hygiene behaviours, which can in turn lead to poor oral health [20]. Symptoms of psychological distress have been found to be associated with tooth loss and use of dental care services in the U.S. [21] and in a Finnish populations [22, 23]. However, in Norway, knowledge about how non-institutionalised older adults perceive their oral health and how often they have check-ups still remains scanty [24]. Furthermore, little is known about the extent to which psychological distress affects the oral health of Norwegian elderly $[21,24]$.

The aim of this study was two-fold: i) to describe Norwegian elderly's self-rated oral health and levels of psychological distress; and ii) to examine the relationship between psychological distress and self-rated oral health while controlling for oral status, smoking, dental attendance and sociodemographic characteristics.

\section{Methods \\ Study population}

The data for this study were retrieved from a national Norwegian cross-sectional study conducted by Statistics Norway (SSB) in 2012: "The Living Conditions study Health, health care and social contact" [25]. A representative random sample of 10,000 Norwegians aged 16 years and older was drawn, stratified by gender, age group and region of residence, from SSB's demographic/ population database BEREG, a database that is updated from The Central Population Register. Of the total drawn from the database, 229 persons had died or were living abroad, consequently, these were not invited to participate, giving a gross sample of 9771 (100\% of the invited participants) persons of whom 4111 declined to participate $(42 \%)$ giving a net samples of 5660 people (58\%). For this study, only respondents aged 65 years and above were used for the analyses $(n=949)$.

The samples were balanced in respect of gender, age and region of residence where everyone in the household was considered as one unit [25].

\section{Data collection process}

Persons in the study were invited to participate by a letter from the SSB, which provided information in Norwegian regarding the purpose of the study, the procedures and actions taken to ensure confidentiality and stating that they would be contacted by telephone for an interview. Data collection involved a combination of a phone interview and a follow-up self-administered questionnaire. Before the interview started, all respondents consented to participate. The follow-up questionnaire was sent to the participants two to three weeks after the 
phone interview and could be completed either on paper or on a web site.

\section{Instruments}

Self-reported oral health, which was the dependent variable in the study, was assessed with one question in the follow-up questionnaire: "How do you perceive your dental health to be?" Five response options were provided: "Very poor", "poor", "neither poor nor good", "good", or "Very good".

Psychological distress, which was the primary predictor in this study, was assessed using the Hopkins Symptoms Checklist - 25 (HSCL-25). HSCL-25 is a shortened version of an original 90 items questionnaire (HSCL-90) and is one of the most commonly used questionnaires to measure the prevalence of mild psychological distress in the population [26-29]. A Norwegian version of this instrument has been validated and used for research and clinical purposes since the late $1980 \mathrm{~s}$ [30]. The scale consists in one question followed by 25 statements that describe symptoms of two major components of psychological distress, Anxiety and Depression: "Specify how much each problem has plagued you or caused trouble during the past 14 days? Each statement was rated by the participants on a four point Likert scale", with each symptom being rated on a 4-point scale (1= "Not at all", 2 = "A little", 3= "Quite a bit", and 4 $=$ "Extremely"). The first ten items in the HSCL-25 questionnaire concern anxiety symptoms and the following 15 items concern depression symptoms. A total mean score $\geq 1.75$ indicates psychological distress at a case level [31]. The overall internal consistency for the HSCL-25 was high (alpha $=0.95)$. All individual items of the HSCL-25 are presented in Table 1.

Other control variables in this study include oral status, smoking, dental attendance, and sociodemographic

Table 1 Proportions of responses to each item on the Hopkins Symptom Checklist-25 ( $n=949)$

\begin{tabular}{|c|c|c|c|c|c|}
\hline Item & Not at all & A little & Quite a bit & Extremely & Mean (SD) \\
\hline 1. Headache & 73.9 & 22.1 & 2.6 & 0.5 & $1.3(0.6)$ \\
\hline 2. Tremor & 86.0 & 9.7 & 1.8 & 0.6 & $1.2(0.4)$ \\
\hline 3. Lassitude or dizziness & 66.2 & 27.9 & 4.1 & 0.5 & $1.4(0.7)$ \\
\hline 4. Nervousness, restlessness & 66.5 & 29.0 & 3.2 & 0.7 & $1.4(0.6)$ \\
\hline 5. Suddenly scared for no reason & 88.3 & 9.3 & 1.8 & 0.2 & $1.1(0.4)$ \\
\hline 6. Increasingly fearful or anxious & 85.7 & 11.1 & 2.2 & 0.1 & $1.2(0.6)$ \\
\hline 7. Palpitations, heart beat running away & 77.9 & 18.2 & 1.8 & 0.2 & $1.3(06)$ \\
\hline 9. Bouts of anxiety or panic & 91.7 & 6.5 & 0.8 & 0.2 & $1.1(0.4)$ \\
\hline 10. So restless that it is difficult to sit still & 84.7 & 12.9 & 1.3 & 0.5 & $1.2(0.5)$ \\
\hline 11. Lack of energy, everything goes slower than usual & 40.8 & 20.2 & 9.5 & 2.0 & $1.7(0.8)$ \\
\hline 12. Blaming yourself for things & 63.5 & 30.2 & 4.6 & 0.7 & $1.4(0.7)$ \\
\hline 13. Tearfulness & 76.0 & 20.0 & 2.8 & 0.7 & $1.3(0.5)$ \\
\hline 14. Thoughts about taking your life & 96.3 & 2.4 & 0.7 & 0 & $1.0(0.2)$ \\
\hline 15. Poor appetite & 90.1 & 7.9 & 1.3 & 0.3 & $1.1(0.5)$ \\
\hline 16. Difficulty falling asleep, staying asleep & 55.6 & 33.6 & 7,6 & 2.5 & $1.6(0.7)$ \\
\hline 17. Sense of hopelessness about the future & 74.4 & 22.1 & 2.4 & 0.6 & $1.3(0.5)$ \\
\hline 18. Depressed, melancholy & 78.4 & 18.4 & 1.8 & 0.4 & $1.2(0.6)$ \\
\hline 19. Feeling of loneliness & 74.3 & 21.1 & 3.5 & 0.5 & $1.3(0.6)$ \\
\hline 20. Loss of sexual desire and interest & 53.5 & 29.7 & 9.7 & 3.8 & $1.6(0.8)$ \\
\hline 21. Feeling of being cheated in a trap or trapped & 93.8 & 5.0 & 0.5 & 0.4 & $1.0(0.3)$ \\
\hline 22. Very worried or upset & 70.3 & 25.6 & 3.4 & 0.4 & $1.3(0.6)$ \\
\hline 23. No interest in anything & 87.2 & 10.5 & 1.4 & 0.4 & $1.1(0.5)$ \\
\hline 24. Feeling everything is an effort & 75.2 & 20.2 & 3.1 & 0.9 & $1.3(0.6)$ \\
\hline 25. Feeling useless & 79.3 & 17.1 & 2.6 & 0.9 & $1.2(0.5)$ \\
\hline Anxiety mean score & & & & & $1.2(0.3)$ \\
\hline Depression mean score & & & & & $1.3(0.3)$ \\
\hline HSCL-25 total mean score & & & & & $1.3(0.3)$ \\
\hline
\end{tabular}

When numbers in columns do not equal $100 \%$, there is internal drop-out in the questionnaire 
characteristics. Oral status was assessed with one variable: Number of teeth present. "Roughly, how many of your own teeth do you have left?" which was answered by choosing one of four response options: 1) "20 teeth or more", 2) "10-19 teeth", 3) "1-9 teeth", and 4) "none". Two variables assessed habits that could have an impact on dental status and oral health: Smoking habits and dental attendance. Smoking was assessed with the question: "Do you smoke?" to which the respondents answered "yes" or "no". Dental attendance was assessed with the question: "When did you last visit a dentist?", which were answered by choosing one of five response choices: 1) "6 month ago or less", 2) "7-12 months ago", 3) "1-2 years ago" 4) "more than two years but less than five years ago", 5) "more than 5 years ago".

Gender, Age group (65-74 years and 75+ years), and Civil Status (i.e. living with partner or Single) were used as selected sociodemographic characteristics.

\section{Statistical analysis}

Descriptive statistics was used to address the first objective of our study. Self-rated oral health was dichotomised: 1) Good oral health (comprising the response alternatives "Very good" and "Good"), and 2) Poor oral health (comprising the response alternatives "Neither good nor poor", "Poor" and "Very poor"). The individual items of the HSCL-25 and the Anxiety and Depression components are presented as means $(\mathrm{M})$ and standard deviations (SD), while the total score of the HSCL-25 is presented as prevalence of individuals with mean score above or below the 1.75 cut-off, i.e. individuals with lower or higher levels of psychological distress [31].

In order to address the second objective of our study, logistic regressions were performed. Before performing the Logistic regression analysis, the responses to self-assessed number of teeth present were collapsed into two categories (20 teeth and more vs. 0-19 teeth) and dental attendance into two categories (within 612 months vs. more than 12 months). Those variables that were significant in the univariate analysis were included in a multivariable logistic regression analysis in order to examine the extent to which Psychological distress predicted Self-reported oral health while controlling for the respondents' sociodemographic characteristics, oral health status, smoking habits and dental attendance. The associations are presented as odds ratios (ORs) and 95\% confidence intervals (95\% CI). The Hosmer-Lemeshow goodness-of-fit test was used to examine whether the final model adequately fitted the data. The significance was set at $p>0.05$. All data analyses were performed using the Statistical Package for the Social Sciences (SPSS, Version 24.0, IBM Armonk, NY).

\section{Results}

The participants' ages ranged between 65 to 96 years, with the median age being 69 years (quartile deviation 68-73 years). The sample consisted of $54.4 \%$ (514) women and $45.6 \%$ (431) men. A total of $71.3 \%(n=674)$ rated their oral health as good or very good and $28.7 \%$ (271) rated their oral health as very poor, poor, or neither good nor poor. There were no differences between men and women on how they rated their oral health $\left(\chi^{2}\right.$ 0.093 , df $1, p=0.760)$ or between age groups $\left(\chi^{2} 0.130\right.$, df1, $p=0.718)$.

The individual HSCL-25 items are presented in Table 1. Missing values for each question varied from $0.2 \%$ to $3.3 \%$, with the highest internal loss for the item concerning 'Loss of sexual desire and interest' (3.3\%). For 23 of the 25 items, the missing values were under $1.0 \%$.

In the overall sample, the total mean score of the HSCL-25 was $1.3 \pm 0.32$. The overall score for the Anxiety component was $1.2 \pm 0.3$, the mean score for the Depression component was $1.3 \pm 0.3$. Eight per cent of the participants had a total HSCL-25 mean score above the 1.75 cut-off, indicating higher levels of psychological distress, while the prevalence of those having a mean score above the 1.75 cut-off for Anxiety was 6.3\% and Depression was $10.4 \%$. Among the various symptoms listed in the HSCL-25, "Lack of energy" (1.7 \pm 0.8$)$, "Difficulties falling and staying asleep" (1.6 \pm 0.7$)$, and "Loss of sexual desire and interest" $(1.6 \pm 0.8)$ were rated with the highest mean scores. Women had significantly higher HSCL-25 mean scores than men $(1.32 \pm 0.33$ and $1.26 \pm$ 0.30 , respectively; ANOVA: $\mathrm{F}=7.46, p=0.006$ ), and the elderly in the oldest age group had significantly higher HSCL-25 mean scores than the youngest age group mean $(1.36 \pm 0.34$ and $1.27 \pm 0.30$, respectively; ANOVA: $\mathrm{F}=5.99, p=0.003)$.

In Table 2, predictors of self-reported oral health are presented. Totals of $65.4 \%$ and $89.2 \%$ were living with partner and were non-smokers, respectively. Moreover, totals of $65.9 \%$ and $83.2 \%$ had 20 teeth or more and attended a dentist annually, respectively.

In the univariable analysis, the likelihood of perceiving poor oral health was increased for individuals who had symptoms of psychological distress, lived alone, smoked, had fewer than 20 teeth, and for persons' who had not attended the dentist within the past year.

When the model was adjusted for all variables in a multivariable model, the participants who had higher levels of psychological distress were 1.89 times more likely to report poor oral health, even when other factors were controlled. Smokers were 1.83 times more likely to perceive poor oral health than non-smokers and those with fewer than 20 teeth were 3.49-times more likely to perceive poor oral health than those with more teeth. In the final model, living alone and not having attended the 
Table 2 Predictors of self-rated poor oral health among elderly Norwegian adults

\begin{tabular}{|c|c|c|c|c|c|c|c|c|c|}
\hline \multirow[t]{2}{*}{ Variables } & \multirow[t]{2}{*}{ Categories } & \multicolumn{2}{|c|}{ Crude measures } & \multicolumn{2}{|c|}{ Univariable } & \multirow[b]{2}{*}{$P$} & \multicolumn{2}{|c|}{ Multivariable $e^{a}$} & \multirow[b]{2}{*}{$P$} \\
\hline & & $\bar{N}$ & Poor self-rated oral health $\%$ & OR & $95 \% \mathrm{Cl}$ & & $\mathrm{OR}$ & $95 \% \mathrm{Cl}$ & \\
\hline \multirow[t]{2}{*}{ HSCL-25 diagnose } & Mean score $>1.75$ & 75 & 45.3 & 2.21 & $1.37-3.57$ & 0.001 & 1.89 & $1.14-3.15$ & 0.014 \\
\hline & Mean score $\leq 1.75$ (reference) & 870 & 27.2 & 1.00 & & & 1.00 & & \\
\hline \multirow[t]{2}{*}{ Civil status } & Single & 327 & 33.9 & 1.47 & $1.09-1.97$ & 0.009 & 1.16 & $0.85-1.59$ & 0.345 \\
\hline & Living with partner (reference) & 618 & 25.9 & 1.00 & & & 1.00 & & \\
\hline \multirow[t]{2}{*}{ Smoker } & Yes & 102 & 46.1 & 2.36 & $1.55-3.59$ & $<0.001$ & 1.83 & $1.17-2.87$ & 0.008 \\
\hline & No (reference) & 843 & 26.6 & 1.00 & & & 1.00 & & \\
\hline \multirow[t]{2}{*}{ Number of teeth } & 0-19 & 322 & 47.2 & 3.79 & $2.82-5.09$ & $<0.001$ & 3.49 & $2.56-4.76$ & $<0.001$ \\
\hline & $\geq 20$ (reference) & 623 & 19.1 & 1.00 & & & 1.00 & & \\
\hline \multirow[t]{2}{*}{ Dental attendance } & $>12$ month & 153 & 35.3 & 1.48 & $1.02-2.13$ & 0.037 & 0.93 & $0.62-1.40$ & 0.746 \\
\hline & 6-12 month (reference) & 786 & 27.0 & 1.00 & & & 1.00 & & \\
\hline
\end{tabular}

$\mathrm{OR}=$ Odds ratio; $95 \% \mathrm{Cl}=95 \%$ confidence Interval. ${ }^{\mathrm{a}}$ Model adjusted for the interaction between $\mathrm{HSCL}-25$ diagnose, civil status, smoking, number of teeth, and dental visits

dentist within the past year were not significantly associated with poor oral health. The goodness-of-fit of measurement used in the model was an acceptable fit on the Omnibus test of model coefficient $\left(x^{2}\right.$ 92.98, $\left.p>0.001\right)$ and Hosmer and Lemeshow test $\left(\chi^{2} 2.61, p=0.760\right)$. The factors used as predictor in the model explained $13.5 \%$ of the variance of perceived poor oral health (Nagelkerke's $R^{2}$ 0.135).

\section{Discussion}

The first objective of our study was to describe oral health and psychological distress among Norwegian elderly. The majority of the elderly in our sample were non-smokers, had 20 teeth or more, and had attended a dental check-up within the past 12 months. Nearly one-third of the elderly reported having poor oral health, and $8 \%$ had higher levels of psychological distress. Among the symptoms listed in the HSCL-25, the most frequently reported problems were lack of energy and difficulties falling and remaining asleep. There were no differences between men and women, or between age groups, in the extent to which they rated their oral health, though women and those in the oldest age group showed higher levels of psychological distress than men and those in the youngest age group, respectively. The second objective of our study was to examine the relation of psychological distress with perceived oral health, controlling for sociodemographic characteristics, smoking, oral status, and dental attendance. The likelihood of reporting poor oral health was independently associated with higher levels of psychological distress while controlling for the other independent variables. Smoking and, especially, having fewer than 20 teeth were also highly significant predictors of poor oral health.

Nearly $66 \%$ of the elderly in our sample had 20 teeth or more, confirming the high proportion of elderly people in Norway who retained their natural teeth, as shown in earlier studies [14,32-34], which is considered essential to maintain adequate chewing function and normal oral health-related quality of life [35, 36].

In line with our findings, a study carried out in nine European countries showed that the occurrence of symptoms of depression in older people living at home varied between 8.0 and $23.6 \%$, with a higher prevalence in women than in men [37]. Although we found the prevalence of Norwegian elderly with higher levels of psychological distress was somewhat low, symptoms such as lack of energy and difficulties falling and remaining asleep were commonly reported. Such symptoms might give an indication of mood and psychological distress and should therefore be regarded in light of their possible impact on the elderly's oral health. Furthermore, the prevalence of psychological distress is likely to increase in future, alongside the increase in the ageing population, and this represents a challenge in Norway and other countries [38, 39].

Our findings relative to the association of psychological distress with oral health are consistent with the literature. Previous studies have in fact found an increased risk for impaired oral health among adults with anxiety and depressive symptoms [21, 22]. For example, in a Finnish study [23], elderly with symptoms of anxiety or depression were almost twice as likely to experience poor oral health. Women with high rates of depressive symptoms had more negative attitude toward preserving their natural teeth, used sugary products more frequently and did not attend for dental check-ups regularly, compared with non-depressed women. Further, depressive symptoms were associated with edentulousness among non-smoking men and symptoms of anxiety were significantly associated with lower tooth brushing frequency [21, 23]. Similarly, in a study on a U.S. 
population, Okoro et al. found that adults with psychological disorders such as depression and anxiety were less likely to attend oral health services and to have tooth loss or had one or more teeth removed than those without such disorder, after controlling for multiple confounders [21].

Higher levels of psychological distress are often associated with loss of energy and might result, for example, in less effective dental hygiene and difficulty following-up routines such as general dental care attendance. Dry mouth is a common complaint in older people, persons suffering from dryness of the mouth are likely to experience several oral problems, including high levels of caries, in addition to difficulties in chewing, eating and communicating [36]. The appetite often declines alongside interest in cooking meals. This can lead to more pronounced loss of energy due to lack of nutrition [20] and such persons show less interest in socialising with other people.

In our study, we also found that the highest adjusted odds ratios were observed for having fewer than 20 teeth, which is also in line with the literature [33, 40, 41]. Musacchio et al. [42] found that tooth loss impacts on general health and is a risk factor for malnutrition, disability, loss of self-sufficiency, and deterioration in quality of life, and having fewer teeth was associated with social lifestyle factors in a population of elderly Italians. Despite an increasing number of people retaining their natural teeth throughout life, the prevalence of oral diseases increases among the institutionalised elderly, their objective need for dental treatment is therefore even greater than before $[38,43]$.

Ekback et al. [39] showed that elderly persons missing many teeth were less likely to be satisfied with their oral condition than those missing only a few or no teeth. Individuals who perceived they had poor general health, smoked daily, had tooth loss, experienced toothache, had difficulties with chewing, and reported bad breath were less likely than their counterparts to be satisfied with their oral health status.

\section{Implications of our findings}

Our findings underline the necessity for dental professionals to be aware of elderly people's levels of psychological distress, as this can have a negative impact on oral health and oral-health related quality of life. Consequently, dental care professionals should consider screening their elderly patients for psychological distress. Moreover, the importance of oral care for older people with psychological distress needs to be emphasised by dental professionals, to reduce the possibility of poorer oral health and deterioration of quality of life in this population.

As tooth loss has a negative impact on how people perceive their oral health is essential in order to maintain adequate chewing function and higher standards of oral health related quality of life [36]. Regular oral health care check-ups are important for helping elderly people maintain their natural teeth through periods when they are in poor health [44, 45]. Therefore, it is important that systematic dental care services for older adults are accessible and affordable $[45,46]$.

\section{Strength and weaknesses of the present study}

The HSCL 25 has been used to assess psychological distress in a number of age and cultural contexts [31, 47, 48]. The way in which the HSCL-25 questionnaires is administrate differs slightly. For example, statements can be delivered face-to-face by a trained interviewer or, like in the present study, the instrument can be self-administered. This may account for some differences in the overall HSCL scores, though evidences suggest that the method of delivery should not have a major impact on the total scores. Nonetheless, in view of this methodological difference, the main emphasis in this analysis has been on the patterns of association rather than absolute differences in the questionnaire scores. Our study is subject to several limitations. First, all data are self-reported. The HSCL-25 was however found to perform well in assessing the symptom severity of anxiety and depression distress among non-elderly in general, and it could therefore be considered as a suitable and valid measure for elderly people. A critical issue in the clinical application of HSCL-25 is to identify cut-off points on the scale that can be used to support decisions about whether further clinical examination is necessary. In our study, the 1.75 cut-off was applied, which has previously shown high validity in a Swedish population [31] and which can be expected to be fairly similar to Norwegian populations in terms of language and cultural context. Another limitation is that the participants' oral status (number of remaining teeth) was self-reported and thus might not correspond to the actual remaining number of natural teeth. However, previous studies have shown a close agreement between self-reported and clinically measured dentition status. [49, 50]. The use of only clinical measures to assess oral health of individuals has been criticized because they fail to consider functional and psychosocial aspects of health and do not adequately reflect the functioning, concerns and perceived needs of individuals $[51,52]$. It is hereby of interest also to include patients` assessment of their wellbeing in the term oral health. In addition, there is a growing interest in dentistry also to assess the influence of oral health on daily life, often labelled oral health-related quality of life (OHRQoL) [52, 53].

Furthermore, tooth loss is considered as an effective marker of the population oral situation. [54]. One of the major limitation of this study relates to possible 
self-selection bias. The participants in this study were probably healthy elderly living at home, able to manage themselves in everyday life, while the ill or less independent elderly who were unable or did not wish to participate might have affected the responses and the results. In a study by Vehkalahti et al., poor oral health have been shown to be a major factor in this kind of population study of the elderly [55]. Thus, taking into account that missing values and drop -out have poorer health, the present findings that differences in dental attendance were mainly related to presence or absence of natural teeth may only relate to healthy women.

\section{Conclusions}

Most of the Norwegian elderly in our sample rated their oral health to be good and relatively few showed higher levels of psychological distress. Higher levels of psychological distress can negatively influence the elderly's oral health, though other factors such as smoking and tooth loss are even stronger predictors of poor oral health. Dental care professionals should consider screening their elderly patients for psychological distress and customize the information about dental care and dental hygiene for this specific population.

\section{Abbreviations}

HSCL-25: Hopkins Symptom Checklist-25

\section{Acknowledgements}

The numerous participants for their efforts in completing the questionnaires. We would also like to thank Statistic Norway (SSB) who conduced the data collection and for letting use the data. This study was supported by Inland University of Applied Sciences in Norway and TkNN in Tromsø, Norway.

\section{Funding}

The study was funded by Department of Public Health, Inland Norway University of Applied Sciences (Elverum, Norway). The Public Dental Health Service. Competence Centre of Northern Norway (Tromsø, Norway); and the Department of Periodontology, Institute of Odontology, The Sahlgrenska Academy, University of Gothenburg (Gothenburg, Sweden).

\section{Availability of data and materials}

The data for this study were retrieved from a national Norwegian crosssectional study conducted by Statistics Norway (SSB) in 2012: "The Living Conditions study - Health, health care, and social contact" (Amdam \& Vrålstad, 2012).

\section{Authors' contributions}

KED did the data processing, contributed to data analysis, interpretation of findings, and to manuscript writing. GC contributed to interpretation of the findings and manuscript writing. BJ did the data processing, carried out data analysis, contributed to interpretation of findings, and manuscript writing. All authors have read and approved the final manuscript.

\section{Ethics approval and consent to participate}

Not applicable.

\section{Competing interests}

The authors declare that they have no competing interests.

\section{Publisher's Note}

Springer Nature remains neutral with regard to jurisdictional claims in published maps and institutional affiliations.

\section{Author details}

'Department of Public Health, Faculty of Social and Health Sciences, Inland Norway University of Applied Sciences, Hamarveien 112, 2418 Elverum, Norway. ${ }^{2}$ The Public Dental Health Service. Competence Centre of Northern Norway (TkNN), Tromsø, Norway. ${ }^{3}$ Institute of Odontology, Department of Periodontology, The Sahlgrenska Academy, University of Gothenburg, Gothenburg, Sweden.

Received: 2 March 2017 Accepted: 22 May 2018

Published online: 31 May 2018

\section{References}

1. World report on ageing and health [http://apps.who.int/iris/bitstream/ 10665/186463/1/9789240694811_eng.pdf?ua=1].

2. Statisticks Norway: Befolkning/nøkkeltall. In. http://www.ssb.no/befolkning/ nokkeltall/befolkning last updated 17. November 2016: Statistisk sentralbyråSSB, Oslo; 2015.

3. Guarnizo-Herreño CC, Watt RG, Pikhart H, Sheiham A, Tsakos G. Socioeconomic inequalities in oral health in different European welfare state regimes. J Epidemiol Community Health. 2013; jech-2013-202714

4. Langballe E, Evensen M. Eldre i Norge: Forekomst av psykiske plager og lidelser (Older Adults in Norway: Prevalence of Mental Problems and Disorders). Oslo: Folkehelseinstituttet; 2011.

5. Petersen PE, Bourgeois D, Ogawa H, Estupinan-Day S, Ndiaye C. The global burden of oral diseases and risks to oral health. Bull World Health Organ. 2005:83(9):661-9.

6. Eke PI, Wei L, Borgnakke WS, Thornton-Evans G, Zhang X, Lu H, McGuire LC, Genco RJ. Periodontitis prevalence in adults $\geq 65$ years of age, in the USA. Periodontology 2000. 2016;72(1):76-95.

7. López R, Smith PC, Göstemeyer G, Schwendicke F. Ageing, dental caries and periodontal diseases. J Clin Periodontol. 2017;44(S18):S145-52.

8. Hugoson A, Sjödin B, Norderyd O. Trends over 30 years, 1973-2003, in the prevalence and severity of periodontal disease. J Clin Periodontol. 2008; 35(5):405-14.

9. Holtfreter B, Kocher T, Hoffmann T, Desvarieux M, Micheelis W. Prevalence of periodontal disease and treatment demands based on a German dental survey (DMS IV). J Clin Periodontol. 2010:37(3):211-9.

10. Eke PI, Dye BA, Wei L, Slade GD, Thornton-Evans GO, Borgnakke WS, Taylor GW, Page RC, Beck JD, Genco RJ. Update on prevalence of periodontitis in adults in the United States: NHANES 2009 to 2012. J Periodontol. 2015;86(5): 611-22

11. Müller F, Naharro M, Carlsson GE. What are the prevalence and incidence of tooth loss in the adult and elderly population in Europe? Clin Oral Implants Res. 2007;18(s3):2-14.

12. Norderyd O, Koch G, Papias A, Kohler AA, Helkimo AN, Brahm C-O, Lindmark $\mathrm{U}$, Lindfors N, Mattsson A, Rolander B. Oral health of individuals aged 3-80 years in Jonkoping, Sweden during 40 years (1973-2013). Swed Dent J. 2015;39(2):69-86

13. Ramsay S, Whincup P, Watt R, Tsakos G, Papacosta A, Lennon L, Wannamethee $S$. Burden of poor oral health in older age: findings from a population-based study of older British men. BMJ Open. 2015;5(12):e009476.

14. Gülcan F, Nasir E, Ekbäck G, Ordell S, Åstrøm AN. Change in oral impacts on daily performances (OIDP) with increasing age: testing the evaluative properties of the OIDP frequency inventory using prospective data from Norway and Sweden. BMC oral health. 2014;14(1):59.

15. Mental health and older adults: Fact sheet [http://www.who.int/ mediacentre/factsheets/fs381/en/].

16. Murray CJ, Vos T, Lozano R, Naghavi M, Flaxman AD, Michaud C, Ezzati M, Shibuya K, Salomon JA, Abdalla S. Disability-adjusted life years (DALYs) for 291 diseases and injuries in 21 regions, 1990-2010: a systematic analysis for the global burden of disease study 2010. Lancet. 2013;380(9859):2197-223.

17. Ólafsdóttir M, Marcusson J, Skoog I. Mental disorders among elderly people in primary care: the Linköping study. Acta Psychiatr Scand. 2001;104(1):12-8.

18. Mykletun A, Knudsen AK, Mathiesen KS. Psykiske lidelser i Norge: Et folkehelseperspektiv. In: Oslo: Nasjonalt folkehelseinstitutt; 2009.

19. Charney D, Reynolds IIIC, Lewis L, Lebowitz B, Sunderland T, Alexopoulos G. Consensus development panel of the depression and bipolar support alliance.(2003). Depression and bipolar support alliance consensus statement on the unmet needs in diagnosis and treatment of mood disorders in late life. Arch Gen Psychiatry. 2003;60(7):664-72. 
20. Pekka P, Pirjo P, Ulla U. Influencing public nutrition for non-communicable disease prevention: from community intervention to national programmeexperiences from Finland. Public Health Nutr. 2002;5(1A):245-52.

21. Okoro CA, Strine TW, Eke PI, Dhingra SS, Balluz LS. The association between depression and anxiety and use of oral health services and tooth loss. Community Dent Oral Epidemiol. 2012;40(2):134-44.

22. Anttila S, Knuuttila M, Ylöstalo P, Joukamaa M: Symptoms of depression and anxiety in relation to dental health behavior and self-perceived dental treatment need. Eur J Oral Sci 2006, 114(2):109-114.

23. Anttila S, Knuuttila MLE, Sakki TK. Relationship of depressive symptoms to edentulousness, dental health, and dental health behavior. Acta Odontol Scand. 2001;59(6):406-12.

24. Birkeland A, Natvig GK. Coping with ageing and failing health: a qualitative study among elderly living alone. Int J Nurs Pract. 2009;15(4):257-64.

25. Amdam S, Vrålstad S. Levekårsundersøkelsen 2012. Helse, omsorg og sosial kontakt (Living Conditions 2012. Health, Care and Social Network). In: Statistics Norway; 2012

26. Derogatis LR, Lipman RS, Rickels K, Uhlenhuth EH, Covi L. The Hopkins symptom checklist (HSCL): a self-report symptom inventory. Behav Sci. 1974; 19(1):1-15.

27. Lipman RS, Covi L, Shapiro AK. The Hopkins symptom checklist (HSCL): factors derived from the HSCL-90. J Affect Disord. 1979;1 (1):9-24.

28. Schauenburg H, Strack M. Measuring psychotherapeutic change with the symptom checklist SCL 90 R. Psychother Psychosom. 1999;68(4):199-206.

29. Parloff MB, Kelman HC, Frank JD. Comfort, effectiveness, and self-awareness as criteria of improvement in psychotherapy. Am J Psychiatr. 1954;111(5): 343-52.

30. Tambs K, Røysamb E. Selection of questions to short-form versions of original psychometric instruments in MoBa. Norsk epidemiologi. 2014;24(12)

31. Nettelbladt P, Hansson L, Stefansson C-G, Borgquist L, Nordström G. Test characteristics of the Hopkins symptom check List-25 (HSCL-25) in Sweden, using the present state examination (PSE-9) as a caseness criterion. Soc Psychiatry Psychiatr Epidemiol. 1993;28(3):130-3.

32. Åstrøm A, Haugejorden O, Skaret E, Trovik T, Klock K. Oral impacts on daily performance in Norwegian adults: validity, reliability and prevalence estimates. Eur J Oral Sci. 2005;113(4):289-96.

33. Åstrøm A, Haugejorden O, Skaret E, Trovik T, Klock K. Oral impacts on daily performance in Norwegian adults: the influence of age, number of missing teeth, and socio-demographic factors. Eur J Oral Sci. 2006;114(2):115-21.

34. Trovik T, Berge T. Do tooth gaps matter? Evaluation of self-assessments: a pilot study. J Oral Rehabil. 2007:34(11):814-20.

35. Kikutani T, Yoshida M, Enoki H, Yamashita Y, Akifusa S, Shimazaki Y, Hirano $H$, Tamura F. Relationship between nutrition status and dental occlusion in community-dwelling frail elderly people. Geriatr Gerontol Int. 2013;13(1):50-4.

36. Willumsen T, Fjaera B, Eide $H$. Oral health-related quality of life in patients receiving home-care nursing: associations with aspects of dental status and xerostomia. Gerodontology. 2010;27(4):251-7.

37. Copeland J, Beekman A, Braam AW, Dewey ME, Delespaul P, Fuhrer R, Hooijer C, Lawlor BA, Kivela S-L, Lobo A. Depression among older people in Europe: the EURODEP studies. World Psychiatry. 2004;3(1):45-9.

38. Samson H, Strand GV, Haugejorden O. Change in oral health status among the institutionalized Norwegian elderly over a period of 16 years. Acta Odontol Scand. 2008;66(6):368-73.

39. Ekbäck G, Åstrøm AN, Klock K, Ordell S, Unell L. Variation in subjective oral health indicators of 65-year-olds in Norway and Sweden. Acta Odontol Scand. 2009;67(4):222-32.

40. Shimazaki Y, Soh I, Saito T, Yamashita Y, Koga T, Miyazaki H, Takehara T. Influence of dentition status on physical disability, mental impairment, and mortality in institutionalized elderly people. J Dent Res. 2001;80(1):340-5.

41. Steele JG, Sanders AE, Slade GD, Allen PF, Lahti S, Nuttall N, Spencer AJ. How do age and tooth loss affect oral health impacts and quality of life? A study comparing two national samples. Community Dent Oral Epidemiol. 2004;32(2):107-14.

42. Musacchio E, Perissinotto E, Binotto P, Sartori L, Silva-Netto F, Zambon S, Manzato E, Chiara Corti M, Baggio G, Crepaldi G. Tooth loss in the elderly and its association with nutritional status, socio-economic and lifestyle factors. Acta Odontol Scand. 2007;65(2):78-86.

43. Henriksen BM, Ambjørnsen $\mathrm{E}$, Axéll T. Dental caries among the elderly in Norway. Acta Odontol Scand. 2004;62(2):75-81.
44. Samson H, Berven L, Strand GV. Long-term effect of an oral healthcare programme on oral hygiene in a nursing home. Eur J Oral Sci. 2009;117(5): 575-9.

45. World Health Organization. International consortium in psychiatric epidemiology. Cross-national comparisons of the prevalences and correlates of mental disorders. Bull World Health Organ. 2000;78:413-26.

46. Petersen PE, Yamamoto T. Improving the oral health of older people: the approach of the WHO global oral health Programme. Community Dent Oral Epidemiol. 2005;33(2):81-92.

47. Strand BH, Dalgard OS, Tamb K, Rogneerud M. Measuring the mental health status of the Norwegian population: a comparison of the instruments SCL25, SCL 10, SCL 5 and MHI-5 (SF 36). Nord J Psychiatry. 2003;57(2):113-8.

48. Sandanger I, Moum T, Ingebrigtsen G, Dalgard O, Sørensen T, Bruusgaard D. Concordance between symptom screening and diagnostic procedure: the Hopkins symptom Checklist-25 and the composite international diagnostic interview I. Soc Psychiatry Psychiatr Epidemiol. 1998;33(7):345-54.

49. Pitiphat W, Garcia RI, Douglass CW, Joshipura KJ. Validation of self-reported oral health measures. J Public Health Dent. 2002;62(2):122-8.

50. Helø LA. Comparison of dental health data obtained from questionnaires, interviews and clinical examination. Eur J Oral Sci. 1972;80(6):495-9.

51. Tsakos G, Marcenes W, Sheiham A. The relationship between clinical dental status and oral impacts in an elderly population. Oral health \& preventive dentistry. 2004;2:(3).

52. Locker D. Clinical correlates of changes in self-perceived oral health in older adults. Community Dent Oral Epidemiol. 1997;25(3):199-203.

53. Dahl KE, Wang NJ, Holst D, Ohrn K. Oral health-related quality of life among adults 68-77 years old in Nord-Trondelag, Norway. Int J Dent Hyg. 2011;9(1): 87-92.

54. Kassebaum N, Bernabé E, Dahiya M, Bhandari B, Murray C, Marcenes W. Global burden of severe tooth loss: a systematic review and meta-analysis. J Dent Res. 2014;93(7_suppl):20S-8S.

55. Vehkalahti M, Siukosaari P, Ainamo A, Tilvis R. Factors related to the nonattendance in a clinical oral health study on the home-dwelling old elderly. Gerodontology. 1996;13(1):17-24.

\section{Ready to submit your research? Choose BMC and benefit from:}

- fast, convenient online submission

- thorough peer review by experienced researchers in your field

- rapid publication on acceptance

- support for research data, including large and complex data types

- gold Open Access which fosters wider collaboration and increased citations

- maximum visibility for your research: over $100 \mathrm{M}$ website views per year

At BMC, research is always in progress.

Learn more biomedcentral.com/submissions 